\title{
Research on Innovation of Traditional Culture Teaching Mode Under the Background of Internet
}

\author{
Yanxia Shen \\ Xi'an Peihua University; Xi'an 710125, China.
}

Keywords: Internet; Traditional culture; Teaching mode; Innovation research.

\begin{abstract}
The traditional Chinese culture, including Peking Opera, calligraphy, poetry, ancient poem, music, couplet, crosstalk, etc. In recent years, under the background of "Internet plus", the teaching mode of either traditional culture form cannot adapt well to development in the Internet age. Therefore, China's traditional culture teaching model innovation is not only urging by Internet + background, but also the actual demand of the information technology era.
\end{abstract}

\section{Introduction}

Some experts say that the Internet has changed China's traditional culture market, it makes traditional Chinese culture more dynamic. However, with the improvement of traditional culture related products, the number of users has been increasing continuously, and the user scale is getting larger and larger. So, what are the similarities between the Internet and traditional Chinese culture? Why should the traditional Chinese culture teaching model be innovative? What are the innovation factors of education in traditional Chinese culture? What is the innovation model of traditional Chinese culture teaching? Here's how:

\section{What are the Similarities between the Internet and Traditional Chinese Culture?}

The Internet has similarities with traditional Chinese culture. They are not only the crystallization of human wisdom, but also the three obvious characteristics: inclusiveness, inheritance and openness.

Inclusiveness. The Internet is remarkably inclusive, because we humans can quickly search through the Internet for information we personally need. The inclusiveness of traditional Chinese culture is that, while actively absorbing and drawing on the foreign national culture, it is also developing, perfecting and strengthening itself. It can be said that Chinese culture is so brilliant is inseparable from its inclusiveness. For example, Buddhism, Taoism and Confucianism are gradually communicating and integrating in Chinese culture.

Inheritance. The Internet also has obvious inheritances, because the information on the Internet contains all the wisdom of mankind, and they have inherited all the ways of obtaining information. The inheritance reflects on that our culture has developed continuously, actively and diligently, even though there have been difficulties. For example, the later people of the Confucian school in China are also actively promoting the ideas of their predecessors.

Openness. Openness is another obvious characteristic of Internet. It is reflects on that, no matter what age, gender and nationality we are, everyone of us can use the Internet to find information they need. Chinese traditional culture is also open to foreign culture, for example, during the Ming and Qing dynasties, although China adopted the policy of isolation, there were still some people who actively engaged in cultural exchanges and other aspects. For example, the "four great inventions" of ancient China also made great contributions to the whole world based on the opening of Chinese national culture. Therefore, traditional Chinese culture is as open as the Internet. 


\section{Why Should China's Traditional Culture Teaching Model be Innovative under the Background of Internet.}

1. Time is running away, human beings are moving forward, and the traditional Chinese culture teaching mode should also be synchronized and innovative, otherwise it will not be able to adapt to the trend of the whole era. In other words, the Internet and Chinese traditional literature teaching should be coordinated in step. Today's society is the age of the Internet, the age of scientific and technological information. In real life, everyone has become inseparable with the Internet media tools, and everyone must learn the latest information, understand the society and the world through the Internet.

Therefore, with the rapid development of the Internet, the thoughts, methods of traditional Chinese culture teaching should be consistent with the Internet development. Only by making bold innovations in traditional culture teaching mode can we keep up with the pace of Internet information age and meet its requirements. We should know that outdated traditional teaching mode, style, etc., cannot meet the need of the age of internet. Therefore, under the background of Internet + , Chinese traditional culture teaching mode must make some changes. It is also important that the innovation of traditional Chinese teaching mode can help to cultivate more creative talents. This is because the traditional culture of our country has a long history, which contains many important factors to cultivate innovative talents. However, it is convenient to search and excavate these innovative factors through Internet media tools to meet the high requirements of today's Internet information era.

2. Under the background of Internet + , only by innovating Chinese traditional culture teaching mode can the Internet media serve the traditional culture teaching better. The Internet contains information about any field, and it can also be used by the Internet media tools in the field of traditional culture teaching. In other words, we can make full use of the Internet to improve the quality, efficiency and scope of traditional Chinese culture teaching. In short, we can use the Internet to serve the teaching of traditional Chinese culture.

\section{What are the Innovation Factors of Education in Traditional Chinese Culture?}

\subsection{Cultivate Students' Critical Thinking Ability.}

In traditional Chinese culture education, one of the innovation factors is to cultivate students' critical thinking ability. For example, the Confucian culture advocated that teach by personal example as well as verbal instrution, Taoist culture holds different attitudes towards Confucian culture and doubts the validity of Confucian culture. In the Song dynasty, for example, Zhu Xi said, "small incredulity makes a big difference." We can see that, Zhu Xi advocated that students should thinking critically during learning. From this, he can judge which student is progressing, which students is backward, which student progress quickly, which student progress slowly, etc. Mencius said, "if believe everything written, it is better to not reading a book", which also profoundly revealed he encouraged students must have their own claims, have their own ideas, rather than believe books and ancient words blindly. etc. This is one of the most basic requirements of Mencius for his apprentice.

\subsection{Focus on cultivating students' interests.}

In traditional Chinese culture education, "paying attention to cultivating students' interest" is one of the important innovation factors. For example, Confucius said, "we can capture the leaders of the army to humiliate them, but we can't insult the aspirations of any ordinary people." Confucius also said that "people who have knowledge are not as good as those who love learning, and those who love learning are not as good as those who are happy to learn." The first sentence is the affirmation of the person's ambition, and then the next sentence is to focus on making sure that students' interests are the starting point of teaching. Undoubtedly, there are two points that cannot be ignored in the concept of Confucius' education. One is that students' aspirations are emphasized, and the other is the interests and hobbies of students, which are often used by people. 


\subsection{Attach Importance to Students' Initiative and Independent Learning.}

In our country traditional culture education, autonomous learning is very important. In "To Learn", for example, both the title and content, has profoundly reflects ancient people's emphasis on active autonomous learning, they not only require students to active learning, autonomous learning, also encourage students to create, and it is also an important concept of Chinese traditional culture education. For example, the famous ancients like Wang Fuzhi, Wang Chong, Sima Qian and Zhang Zai made their original efforts.

\subsection{Pay Attention to the Communication and Debate Among Students.}

It can be said that attach importance of communication and debate is a major innovation factor of education in traditional Chinese culture.

Book "the doctrine of the mean", wrote: "students should be knowledgeable, asking questions, critical thinking, distinguish between right and wrong, stick to their own values", in fact this a few words expressed the process of learning.

Among them, the meaning of " distinguish between right and wrong " is to let students have their own way to judge right and wrong. This concept not only includes the private communication between masters, but also the communication between students, of course, also including the debate. In fact, the purpose of the student communication and debate is not only to make students' minds collide, but also the possibility of a new spark. From this we can see the significance and influence of the communication and debate in Chinese traditional culture.

\section{What Kinds of Innovations are there in the Specific Teaching Mode of Chinese Traditional Culture under the Internet + Background?}

\subsection{Cooperative Inquiry Teaching Mode.}

Communication and debate are a major innovation factor of education in traditional Chinese culture, and cooperative inquiry teaching mode takes advantage of this innovation factor. Here's how: The teacher first divided the students into groups of four, or groups of six. Then, the teacher divided the tasks among the groups and assigned each student a task. After that, each student will find relevant information according to their respective tasks, and the group members can communicate with each other on the group tasks assigned by the teacher, thus completing the task of the group. However, there is one thing that should not be underestimated. The teacher should not only assign tasks to the group, but also divide the tasks for each student. In fact, this is the essence of the innovation of the teaching mode.

\subsection{Self-Learning Teaching Mode.}

It is important to know that Chinese traditional culture has the innovation factor of " self-study ability", and this independent learning teaching model takes advantage of the innovation factor. In fact, there are a lot benefits of this new teaching model, it not only can cultivate students' independent thinking ability, cultivate students' innovation ability, but also promote students to independent problem-solving skills and ability, etc. This kind of teaching mode requires students to have high comprehensive quality and ability to find and solve problems. Not only do students need to have the skills to find network information, they also need to be able to ask critical questions and know how to solve them well. For average students, however, the teacher can also make great efforts to train them, one step at a time, but never spoil things by excessive enthusiasm, because Rome was not built in a day.

So, what exactly is this teaching model? When teaching the relevant content of traditional culture, the teacher should assign homework to the students, so that the students can check the information related to the ancient people through the Internet. Not only that, students also must ask some questions based on finding information, and then gradually verify and solve these problems. students find information on their own, ask questions to themselves, solve the problem by themselves. in fact, this process can give students bring unexpected results, especially in skills improvement. 


\subsection{Problem Situation Teaching Mode.}

This is a very easy to understand, which is creates the innovation in the teaching of situational mode based on the innovation factor of the critical thinking in traditional Chinese culture. The teacher listed the names of the ancients first and asked the students to search the Internet for questions related to the ancients. Then, when they returned to the classroom, they discussed and solved the problem together. however, as a teacher, you must try to introduce students to a problem-solving situation, and the ancients' critical thinking spirit precious subtly conveyed to the students. Teachers should also note that the traditional Chinese cultural content involved must be related to critical thinking of the ancients. Otherwise, it is not convenient for the establishment of situational mode teaching.

\subsection{Case Teaching Mode.}

In traditional Chinese culture, apart from intellectual innovation, it also includes non-intellectual innovation factors, such as the students' aspirations and interests mentioned earlier. Then, aiming at these non-intellectual innovation factors in Chinese traditional culture, we can try to apply the innovation in case teaching mode. Teachers can give students under this assignment, let the student find the important character of Chinese traditional culture Li Shizhen, $\mathrm{Zu}$ Chongzhi through the Internet, learn the lives of these ancient people, let the students write down the fun stories about their ambition. At the same time, teachers can also teach students to follow the example of these ancient people when they grow up. in general, is with the model of case teaching, student summarizes the ancient idea of the typical case, thanks to the Internet, and then, again pointed to teaching, so that the case in the student impression more profound.

\section{Conclusion}

With the development of information technology, the Internet era has arrived, and under the background of the Internet + , the traditional teaching mode of Chinese traditional culture have already failed to keep pace with times. Therefore, both teaching ideas and methods need to be innovated and changed, to be consistent with the development level of The Times and cultivate more and better innovative talents.

\section{Acknowledgements}

Shaanxi Province's Education Science "13th Five-year Plan" Project in 2017: "The application course construction orientation research based on 'Internet + ' thinking of the private colleges and universities" (Subject No. SGH 17H 467)

\section{References}

[1]. Innovation is the fundamental driving force of development [J]. Feng Zhijun, Liu Yanhua, Fang Xin, Mu Rongping, Zhang Wei. Scientific research management. 2015(11)

[2]. The analysis of non-intelligence factors of the national top science and technology award recipients [J]. Li Zuchao, Li Weian, Wang Tiane.

[3]. On the relationship between the spirit of "Shi" and the characteristics of the famous presidents of the universities of the republic of China [J]. Wang Zhan, Ren Jianhua. Modern education science. 2015(07)

[4]. Transformation of information literacy education in the context of MOOC [J]. Huang Ruhua, Li Baiyang. Book intelligence knowledge. 2015(04)

[5]. The establishment of the Confucian theory of mind time: the time theory of Zeng Zi and Zi Si [J]. Wang Zheng. Journal of Hebei normal university (philosophy and social science edition). 2015(01). 
[6]. The consciousness of life consciousness and the "three talents" in the "four sentences" of "horizontal channel" [J]. Wang Xinchun. Philosophy research. 2014(05)

[7]. On Mencius' inheritance and promotion of Confucius' moral education [J]. Feng Wenquan, Feng Biying. Education research. 2013(01)

[8]. "Internet + " era of intelligent campus construction research [J]. Zhao Qiang. China new communication. 2018(03)

[9]. Challenges and countermeasures of education under the new situation of "Internet + " $[\mathrm{J}]$. Zheng guiling, Liu Yun, Han Xiaoli. Modern business and trade industry.

[10]. What the Internet + education will bring to us [J]. Zhang Yongyi. Group words. 2016(12)

[11]. "Internet plus" and online education [J]. Children's competition. 